\title{
A WALKER DESIGNED FOR PARKINSON'S DISEASE PATIENTS BASED ON A SURVEY IN DHAKA, BANGLADESH
}

\author{
DIBAKAR Sarker ${ }^{1 *}$, MARUF UL Karim ${ }^{1}$, MD. SHARJIL Ahamed ${ }^{1}$, \\ FARZANA Sultana ${ }^{1}$, ZAHIDUL Islam ${ }^{2}$

\begin{abstract}
${ }^{I}$ Ahsanullah University of Science and Technology, Department of Mechanical and Production Engineering, Dhaka-1208, Bangladesh, e-mail: dibakarsarker89@gmail.com

${ }^{2}$ Rajshahi University of Engineering and Technology, Department of Industrial and Production Engineering, Rajshahi-6204, Bangladesh
\end{abstract}

\begin{abstract}
A neurodegenerative disorder like Parkinson's disease (PD) causes tremor, rigidity, postural instability and gait problems in early stages and thus poses an undetermined threat to the social and personal lives of the elderly in developing countries due to insufficient survey and research activities. However, several types of assistive devices (AD) are available in the market and the real patients' requirements are often overlooked in their design. This paper presents the process of design and fabrication of an innovative walker for PD patients. This walker has a non-modular foldable design which incentivizes patients to stand up straight and walk without the help of others. A survey on patients battling parkinsonism and practicing doctors was performed in public hospitals in Dhaka, Bangladesh and relevant engineering data was derived from it using Quality Function Deployment (QFD) which can also help visualize further market research opportunities. A finite element analysis (FEA) was performed before the walker was constructed for safety. It was handed to several volunteers for use and their responses were satisfactory. The designed walker may serve as a low-cost AD which is likely to improve a patient's posture and overall lifestyle and therefore, it can act as a means of rehabilitation.
\end{abstract}

KEYWORDS: Assistive Device, Parkinson's Disease, Sandwich-structured Composite, Finite Element Analysis, Ergonomics, Public Awareness

\section{Introduction}

Parkinson's disease (PD) is a neurodegenerative, progressive, and chronic disorder that affects the central nervous system causing various physical predicaments [1], the four fundamental clinical features of it being tremor at rest, rigidity, slow movement and postural instability [2]. It affects about $1 \%$ of the population over the age of 60 [3] and the number of victims by 2030 is likely to be more than double of 2005's [4]. The common gait freezing among the patients which are unlikely to be cured entirely by medical and surgical procedures [5] signifies a brief suspended activity of voluntary motor when facing physical or visual obstacles [6].

Over time, PD patients may develop a fear of falling (FoF) [7] and Kegelmeyer et al. [8] found that, four-wheeled-walker can be a safe ambulatory device with greater consistency of improvement. With these issues in mind, the primary purpose of this project was to design and fabricate an innovative wheeled walker, also called a rollator, that would add values over the existing features of the currently available walkers in the market that might prove to be helpful for maintaining balance in case of Parkinsonian gait.

It would be foldable, compact and easy to handle walking aid with proper brakes and wheels to climb minor obstacles. The design came with a seat for resting and locks for wheels to prevent sliding. The handle was constructed with the intention to help a person stand up straight when 
walking without the need of struggling to push it. Also, from the perspective of a developing country like Bangladesh, it was envisioned to be a low-cost assistive device (AD) without any propulsion system that anyone physically challenged would find fruitful for improving movement and body posture and thus mitigate the difficulties in their day-to-day lives.

Firstly, this paper discusses the scenario of the available ADs and their specific needs for users. Secondly, the survey regarding the needs and issues faced by patients and required engineering applications are presented. Third, an overview of the design, material selection and stress analysis of the proposed walker are provided. Finally, the outcome of the research project and the scope for further improvements and features as well as the future prospects of ADs for Parkinsonism have been explored.

\section{Existing Assistive Device Types for Gait Improvement and Walking Disability}

Constantinescu et al. [9] classified the available varieties of mechanical ADs that are recommended by physical therapists to PD patients based on individual needs into three broad categories: 1. walking sticks and canes that are suitable for patients with moderate level of complications, 2. walkers that are used when canes are insufficient and 3. Scooters and power wheelchairs with hand controls that are for the patients unable to move on their own outside their homes. At present three-legged, four-legged and U-shaped walking aids or walkers are manufactured with the capacity of customisable and specialised features for individual needs. No single AD can compensate for all the complications that PD patients and people with movement difficulty face; whereas, it is not feasible to incorporate every type of feature into one product. In case of other walking disabilities, the available ADs in Bangladesh are mostly conventional and without any regard to cost savings and actual needs of patients.

\section{Methods and Materials}

The methodology of the research consisted of 6 main stages:

1) Ideation: First the possible research problems were brainstormed and finally one was selected due to its highest feasibility of application.

2) Survey questionnaire formation: It consisted of 3 sets of queries: -1. Dichotomous questions, 2. Likert scale questions, 3. Open-ended questions and a comment section. A poster demonstrating the causes, symptoms and behavioural aspects of parkinsonism was created for helping people who were not sufficiently aware of the disease.

3) Data collection: Both online survey and personal interviews were conducted for gathering the necessary data for research. Additionally, accessible local stores selling ADs were visited for gauging the current market scenario.

4) Data analysis: The survey data was converted to engineering requirements using the method of House of Quality (HOQ).

5) Design: The structure of the walker was designed and its stability was subsequently analyzed in a finite element simulation. Suitable materials for parts to be manufactured were selected on the basis of their availability and prices.

6) Manufacture and assembly: The parts, either purchased or manufactured manually, were assembled into the intended shape of the walker.

All these steps are concisely described in Sections 3.1 to 3.6.

\subsection{Survey Scope and Participants}

The survey was performed both online and in person. For face-to-face interview with doctors, patients and their relatives and acquaintances, three of the largest public hospitals in Dhaka, Bangladesh were visited. A total number of 21 patients and 15 doctors were consulted 
in person while 41 people participated in online survey. The patients interviewed in person were aged between 61-73 years and people surveyed online were aged between 23-76 years. The responses to survey questions were compiled and analysed which provided a clear understanding of the user needs that had to be addressed in the design process. Moreover, local markets were visited where the minimum weight bearing capacity of the available walker models was found to be $135 \mathrm{~kg}$ (approximately $298 \mathrm{lbs}$ ). Wheelchairs of various prices are also available which are sometimes prescribed to PD patients by doctors, despite their uncertain effectiveness to help the patients achieve more self-efficacy in movement.

\subsubsection{Survey Challenges and Justification}

The major challenge of the survey was the ignorance of the local people about PD as most of the survey takers were not aware of the major traits of the disease. This issue can be attributed to social disregard to diseases and the problems of the elderly, lack of awareness about information sources, and scarcity of PD assistive devices. There is also no reliable data on the number of people affected by PD in Bangladesh. Moreover, only a limited number of people affected by PD could be reached for survey due to scarcity of information and resources.

The implications of the disease were demonstrated to the patients and individuals who needed it when surveying as a means of justifying the survey approach. The survey team also attempted to reach out relatives and acquaintances of the patients and doctors who were eligible for participation in online with a poster presenting the implications of PD.

\subsubsection{Survey Analysis for Data Extraction}

From the survey of patient requirements, the main takeaways were ability to stand upright while walking with the walker, ability to sit and walk or stand and walk, standard weight limit, collapsibility, lever to step up a curb, height adjustable features, bar instead of handles, nonmodular design and cost effectiveness. An HOQ relationship matrix [10] was developed as part of Quality Function Deployment (QFD) for the walker which has been shown in Table 1. The relationships between customer requirements and engineering specifications have been demonstrated below.

- Static friction coefficient: Physical property of material deformation characteristics and surface roughness related to number of wheels and brake system.

- Force to push: Optimum force to move the walker while standing upright or sitting.

- Weight of the walker: Related to easy cleaning and low maintenance cost.

- Force to turn: Easy manoeuvrability related to handlebar.

- Force analysis: For collapsibility, seat adjustments, manoeuvrability, weight limit, handlebar position and four-wheeled features.

- Force to step up curb: Requirement of a lever to adjust the wheel to ride a curb along a path.

- Breaking force for terrains: Related to brakes; force to cause damage on different terrains.

- Need only one person: Collapsibility and non-modularity is required for any patient when alone.

- Force to squeeze breaks: Force required on breaks by hands.

- Force for break slip: Measurement of force for the break system to slip.

The survey suggests that no single walker in the current market provides all the specifications the patients and the professionals that took part in it thought to be crucial. Therefore, the major outcomes of the survey provided the motivation for the design of the walker with a view to meeting the needs to the greatest possible extent while keeping the cost minimum. 
Table 1 The HOQ chart for walker feature selection
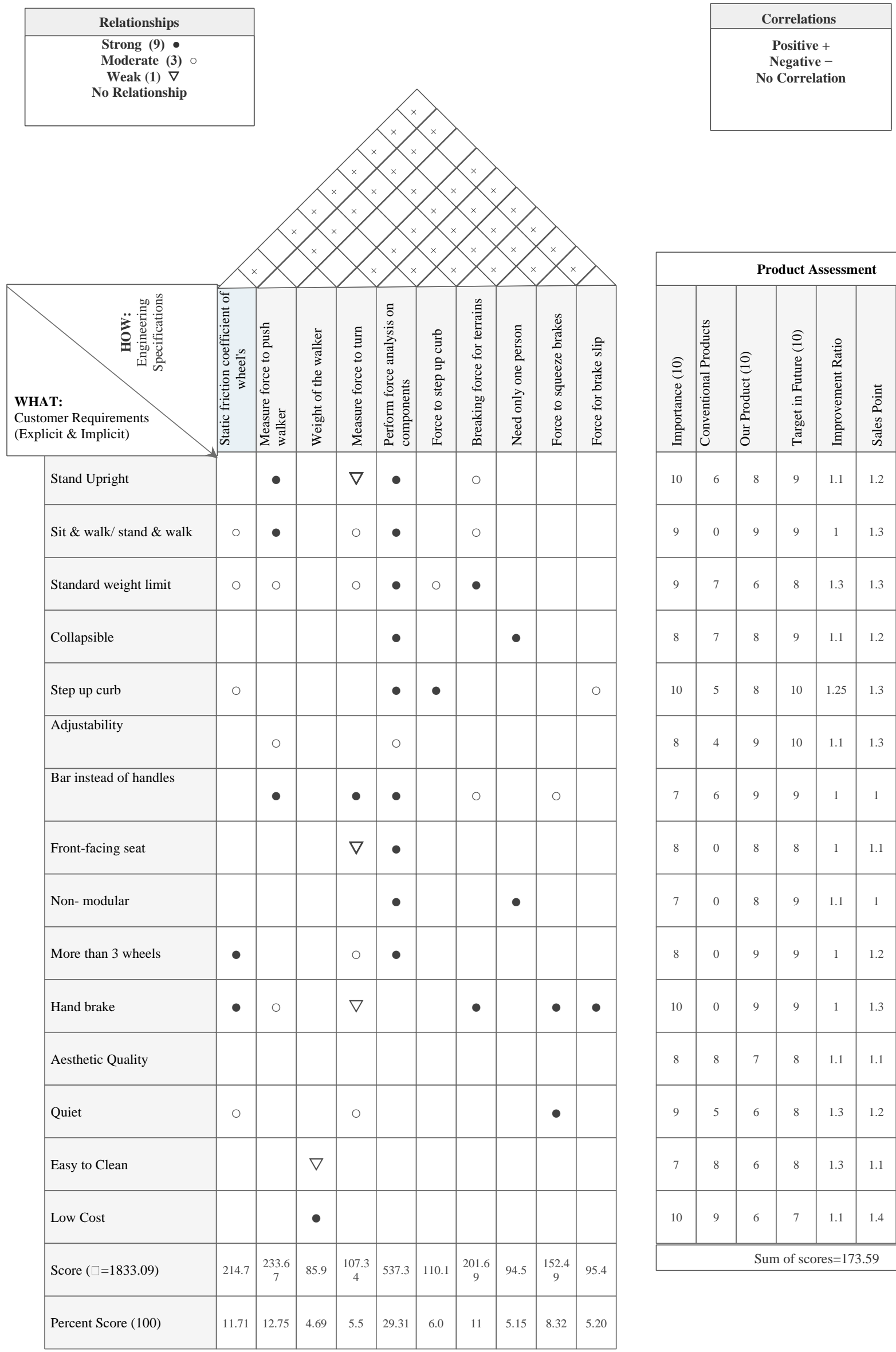

\section{WHAT:}

Customer Requirements plicit \& Implicit)

\begin{tabular}{|c|c|c|c|c|c|c|c|c|c|c|}
\hline Stand Upright & & $\bullet$ & & $\nabla$ & - & & 0 & & & \\
\hline Sit \& walk/ stand \& walk & 0 & - & & 0 & - & & 0 & & & \\
\hline Standard weight limit & 0 & 0 & & 0 & - & 0 & - & & & \\
\hline Collapsible & & & & & - & & & - & & \\
\hline Step up curb & 0 & & & & - & - & & & & 0 \\
\hline Adjustability & & & & & & & & & & \\
\hline Bar instead of handles & & $\bullet$ & & $\bullet$ & $\bullet$ & & 0 & & 0 & \\
\hline Front-facing seat & & & & $\nabla$ & - & & & & & \\
\hline Non- modular & & & & & - & & & - & & \\
\hline More than 3 wheels & - & & & 0 & - & & & & & \\
\hline Hand brake & - & 0 & & $\nabla$ & & & - & & - & - \\
\hline Aesthetic Quality & & & & & & & & & & \\
\hline Quiet & 0 & & & 0 & & & & & - & \\
\hline Easy to Clean & & & $\nabla$ & & & & & & & \\
\hline Low Cost & & & - & & & & & & & \\
\hline Score $(\square=1833.09)$ & 214.7 & $\begin{array}{c}233.6 \\
7\end{array}$ & 85.9 & $\begin{array}{c}107.3 \\
4\end{array}$ & 537.3 & 110.1 & $\begin{array}{c}201.6 \\
9\end{array}$ & 94.5 & $\begin{array}{c}152.4 \\
9\end{array}$ & 95.4 \\
\hline Percent Score (100) & 11.71 & 12.75 & 4.69 & 5.5 & 29.31 & 6.0 & 11 & 5.15 & 8.32 & 5.20 \\
\hline
\end{tabular}

\begin{tabular}{|c|c|c|c|c|c|c|c|}
\hline \multicolumn{8}{|c|}{ Product Assessment } \\
\hline 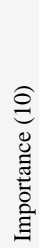 & 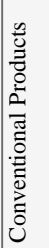 & 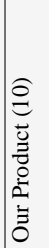 & 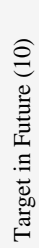 & 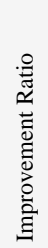 & 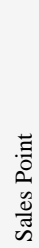 & $\begin{array}{l}\mathscr{U} \\
\tilde{D} \\
\tilde{U}\end{array}$ & 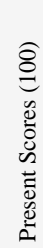 \\
\hline 10 & 6 & 8 & 9 & 1.1 & 1.2 & 13.2 & 7.6 \\
\hline 9 & 0 & 9 & 9 & 1 & 1.3 & 11.7 & 6.7 \\
\hline 9 & 7 & 6 & 8 & 1.3 & 1.3 & 15.2 & 8.8 \\
\hline 8 & 7 & 8 & 9 & 1.1 & 1.2 & 10.56 & 6.1 \\
\hline 10 & 5 & 8 & 10 & 1.25 & 1.3 & 16.2 & 9.3 \\
\hline 8 & 4 & 9 & 10 & 1.1 & 1.3 & 11.4 & 6.6 \\
\hline 7 & 6 & 9 & 9 & 1 & 1 & 7 & 4.03 \\
\hline 8 & 0 & 8 & 8 & 1 & 1.1 & 8.8 & 5.07 \\
\hline 7 & 0 & 8 & 9 & 1.1 & 1 & 7.7 & 4.4 \\
\hline 8 & 0 & 9 & 9 & 1 & 1.2 & 9.6 & 5.5 \\
\hline 10 & 0 & 9 & 9 & 1 & 1.3 & 13 & 7.5 \\
\hline 8 & 8 & 7 & 8 & 1.1 & 1.1 & 9.7 & 5.6 \\
\hline 9 & 5 & 6 & 8 & 1.3 & 1.2 & 14.08 & 8.1 \\
\hline 7 & 8 & 6 & 8 & 1.3 & 1.1 & 10.01 & 5.8 \\
\hline 10 & 9 & 6 & 7 & 1.1 & 1.4 & 15.4 & 8.9 \\
\hline \multicolumn{8}{|c|}{ Sum of scores $=173.59$} \\
\hline
\end{tabular}




\subsection{Design}

For the design of the four-wheeled-walker, the following qualities derived from the survey were considered indispensable from engineering viewpoint: -

- The walker must be lightweight and robust

- A foldable seat behind the user for resting

- Collapsible and space-saving

- Wheels large enough to overcome common obstacles

- Easy manoeuvrability for turning left or right

- Adjustable height

- Aesthetically appealing

- Handle must provide a straight body posture

- Ability to mount a curb when walking

- User can seat and walk or stand and walk

- Effective handbrakes for stoppage

For collapsibility, the idea of folding mechanism [11] usually incorporated in foldable wheelchairs was modified to the design needs of the walker with a view to compacting the storage and transportation. This mechanism would also work as a link between the two frames carrying the load of the patient while sitting the seat or walking while holding the handlebar. The seat, designed to be behind the user for safety and comfort, consists of two equal halves that mate when they are pulled down and open when they are pulled up. It was decided to be set at a minimum $400 \mathrm{~mm}$ above the ground as per average South East Asian sitting popliteal height available in DINED anthropometric database of Delft University of Technology [12]. Several other components were designed for the walker which have been briefly discussed in Section 3.3 .

\subsection{Components and Features}

The design of the walker consists of different mechanical parts. Their names and uses have been briefly discussed below.

T-bar: The main part of the folding mechanism is the middle T-shaped handlebar that connects all the interlocking components. The two interlocking bars can be pulled to force the instrument panels to collapse. It was designed for adjustable range that allows most users to hold it while keeping the arms parallel with the horizontal and walk with a straight spinal posture (lumber lordosis) which can possibly help them recover from postural abnormality [13]. It is also easy to grab and rest while both sitting and standing.

Side frames or Side panels: They are a pair of matching panels or frames, one on each side of the user, attached by the handlebar and folding mechanism that carry the load of the user. They are designed to be able to fold compactly side to side.

Crossbar linkages: They work as a link between the middle T-bar and side frames that provides collapsibility to the walker.

Collars: They can slide over the vertical portion of the T-bar and lock onto holes of the Tbar and crossbars as a height adjusting mechanism. 
Brackets: Their purpose is to attach other components to the side frames with certain degrees of freedom.

Wheels: Swivel caster wheels of 8-inch diameter were proposed to be mounted below the side frames because they are commonly available and can overcome small obstacles and curbs easily. Also, caster flutter is expected to be minimum in this scenario because PD patients are supposed to walk slowly [14]. Locally available caster wheels were found to have a minimum load bearing capacity of more than $136 \mathrm{~kg}$ (approx. $300 \mathrm{lbs}$ ) when four wheels are combined together.

Brakes: Band brakes were chosen for their simplicity of incorporation and maintenance as well as their ability to exert sufficient force.

Grips: These are rubberised grips for holding and manoeuvring the T-bar. Due to the height adjustability of the T-bar, the user is able to grip it at elbow height for pushing the walker while keeping the arms horizontal and maintaining the wrists and the spine straight.

\subsection{Materials Selection}

One of the primary concerns for a patient of Parkinson's disease is the weight of their walker and hence a range of lightweight composite materials were considered due to their frequent use and adaptation to ADs from aerospace technology [9]. After due research, HexPly 8552 unidirectional (UD) carbon prepreg (AS4 fiber) - a type of carbon fiber reinforced polymer (CFRP) composite commercially produced by Hexcel Corporation, USA and PVC rigid grade were selected for manufacture of the side frames. Therefore, they were chosen based on several salient features they offer that are likely to serve the design purpose. Carbon fibers show low weight and high stiffness and hence CFRPs have applications requiring high strength-to-weight ratios [15]. HexPly 8552 comes with a standard version [16] containing a cured epoxy resin matrix which depicts strength, adhesion, and heat and chemical resistance [17]. As a continuous-fiber reinforced prepreg (i.e. short for preimpregnated) laminate, it has high strength and stiffness in one direction $\left(0^{0}\right.$ orientation) which can endure the walker's sitting load and furthermore, prepregs give good mechanical performance with easy processing at low costs [18].

A polyvinyl chloride (PVC) rigid grade foam, sandwiched between plies or faces of the specified CFRP bonded by epoxy adhesive, was considered to design the side frames or sandwich panels. It works as a core and is subjected to shear stresses, has lower density and modulus of elasticity than the CFRP plies have. One of the plies is subjected to compressive stresses and the other faces tensile stresses while both being supported by the core. The bending stiffness of a sheet is proportional to the cube of its thickness [19] and hence bending stiffness increases substantially with the increase of core (PVC) thickness [20].

\subsection{Finite Element Analysis (FEA) for Design Verification}

A static structural FEA was performed to make sure the manufactured walker would not cause any trouble to users regarding safety. The side frames were considered to be most vulnerable due to the normal force exerted by the user through the seats and the normal force from the caster wheels in the reverse direction, causing a flexural or bending stress. SolidWorks simulation add-in was used to predict the failure behavior of the side frame design and perform FEA in the axial direction of the UD CFRP. The material property data available on online [16] was used to for HexPly 8552 UD carbon prepreg and the parameters for PVC rigid grade was used from SolidWorks built-in materials data. The carbon prepreg plies are available in 0.13 $\mathrm{mm}$ plies and 3 piles were modelled on each side of the $19.05 \mathrm{~mm}$ sandwiched PVC because the simulated results showed extreme to moderate deformations with the initial 1 and 2 plies of 
prepreg. Thus, the total width of each side frame disregarding any adhesive layer was 19.83 $\mathrm{mm}$.

In the simulations, the maximum static load given on the walker was $136 \mathrm{~kg}$ (approx. 300 lbs) so that it met the current market standard. The series of analyses showed in Figure 1-4 were performed on the 8 holes that carried the load of the seat with the help of steel screws. Hence, each of the holes faced a load of $34 \mathrm{kgs}$ (approx. $75 \mathrm{lbs}$ ). The diameter of each hole was taken to be $7 \mathrm{~mm}$. The mesh size selected was $3 \mathrm{~mm}$ as per computer hardware performance. Figure 1 below shows that the side frame remained in the least von Mises stress zone denoted by the color blue.

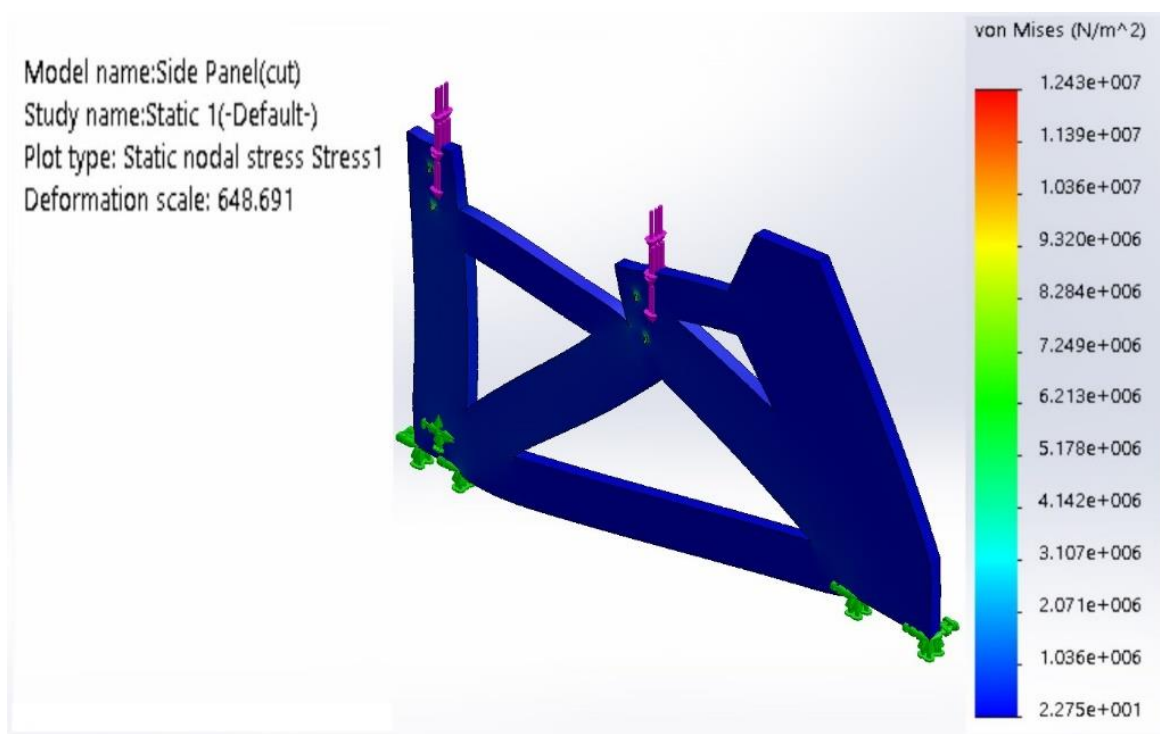

Fig. 1 von Mises stress analysis

In the static strain analysis in Figure 2, the amount of strain was infinitesimal and in the displacement simulation in Figure 3, the maximum displacement was found around the upper holes, indicated by the red zone, where the seat is attached with the frame. The value of this deflection is shown to be $1.67 \times 10^{-1} \mathrm{~mm}$ which is barely recognizable in reality.

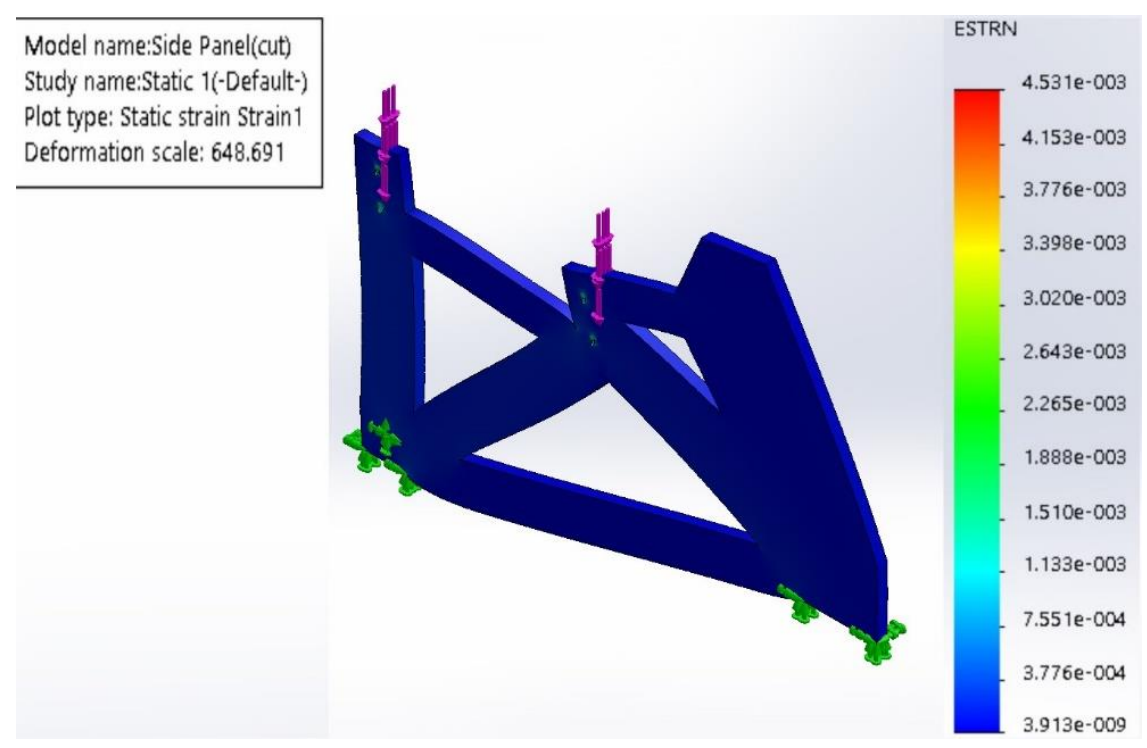

Fig. 2 Static strain analysis 


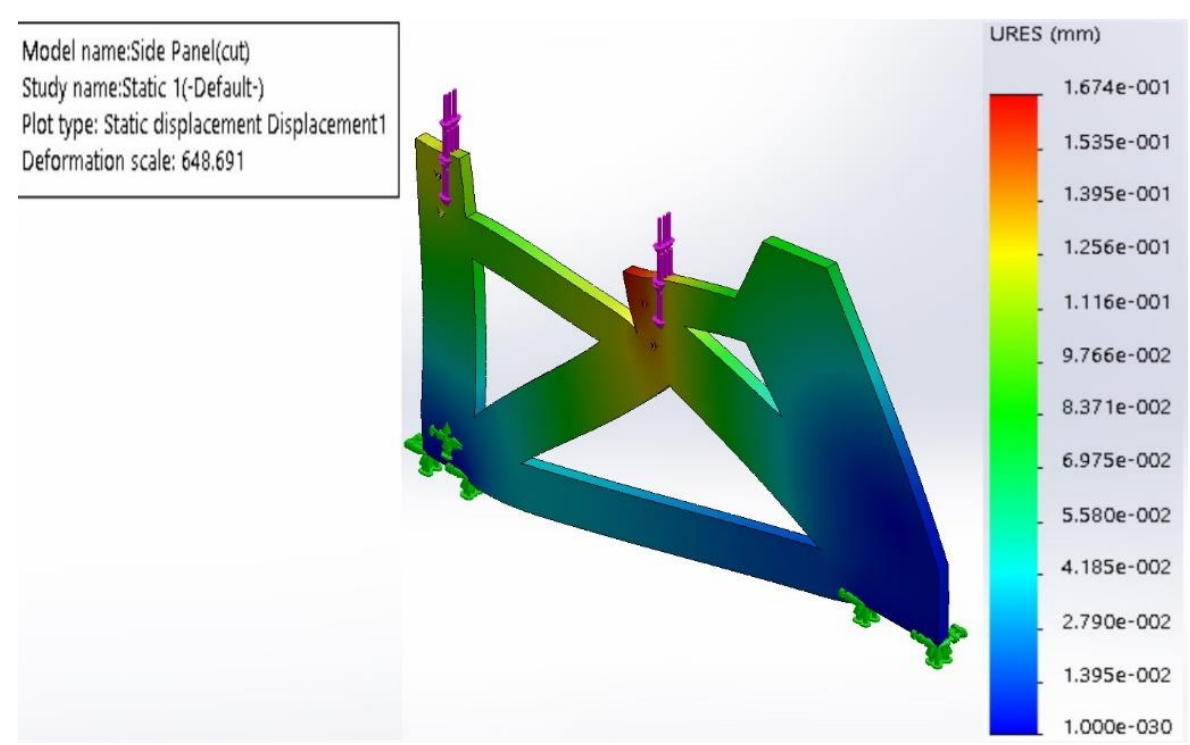

Fig. 3 Static displacement analysis

The minimum Factor of Safety (FOS) under the von Mises criterion [21] was found to be 9.9 as shown in Figure 4. Therefore, the simulation justified the design to be above the minimal safe range for the common user.

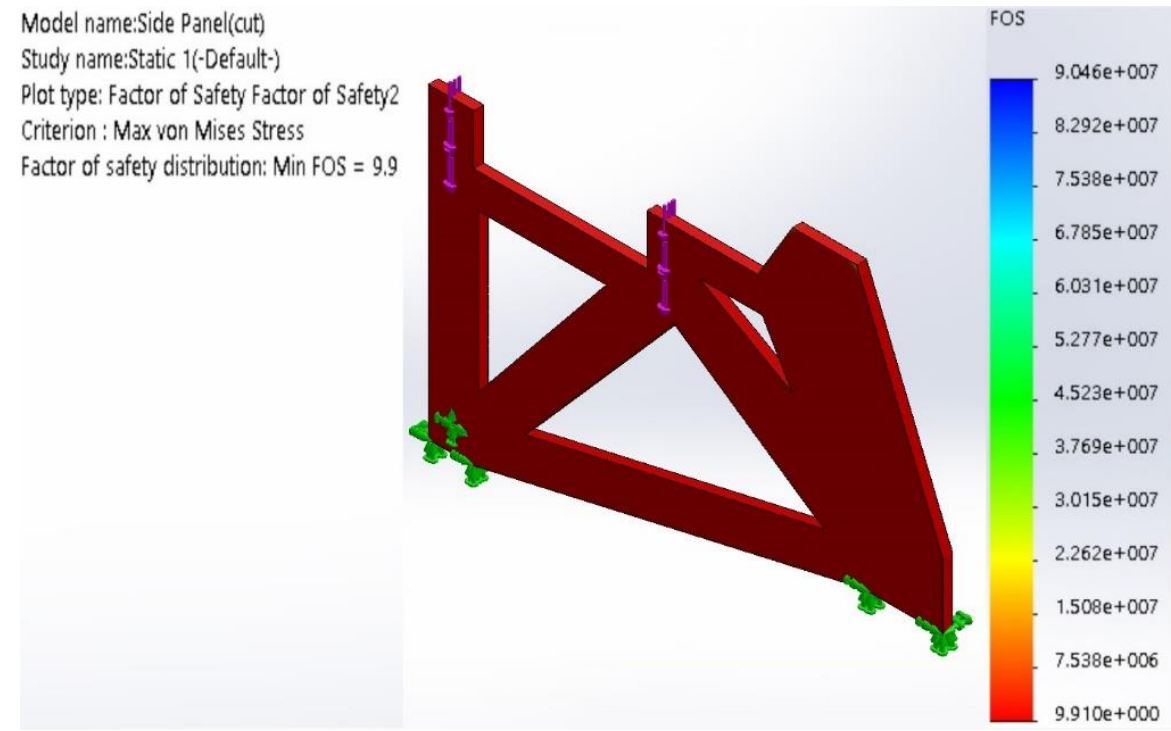

Fig. 4 FOS under von Mises Criterion

\subsection{Manufacturing and Assembly of the Walker}

Aluminum (Al) was considered ideal for manufacturing the T-bar, linkages, collars and brackets. The Al structural alloy (6061-T6) was finally selected due to its high strength-toweight ratio, corrosion resistance, machinability and widespread availability in the local market. Its minimum yield strength is $240 \mathrm{MPa}$ which is close to that of A36 steel, while its weight being about one-third that of steel [22].

The planning of design and fabrication process of the walker was conducted by basic product design guidelines such as Design for Manufacturing (DFM), Design for Assembly (DFA) [23] and manufacturing process selection [24] with a view to minimizing time and cost of manufacture and optimizing the ease of assembly. The manufacturing processes required have been listed in Table 2 and the final walker after assembly is shown in Figure 5. 
Table 2 Manufacturing processes for the walker

\begin{tabular}{|l|l|}
\hline \multicolumn{1}{|c|}{ Part } & \multicolumn{1}{c|}{ Required Manufacturing Process } \\
\hline Side frames (PVC, CFRP) & Epoxy adhesive, Shearing, Drilling \\
\hline T-bar, Crossbar linkages & Drilling, Gas Metal Arc Welding (GMAW) \\
\hline Collars & Drilling, Tapping, Turning \\
\hline Brackets & Drilling, Bending \\
\hline
\end{tabular}

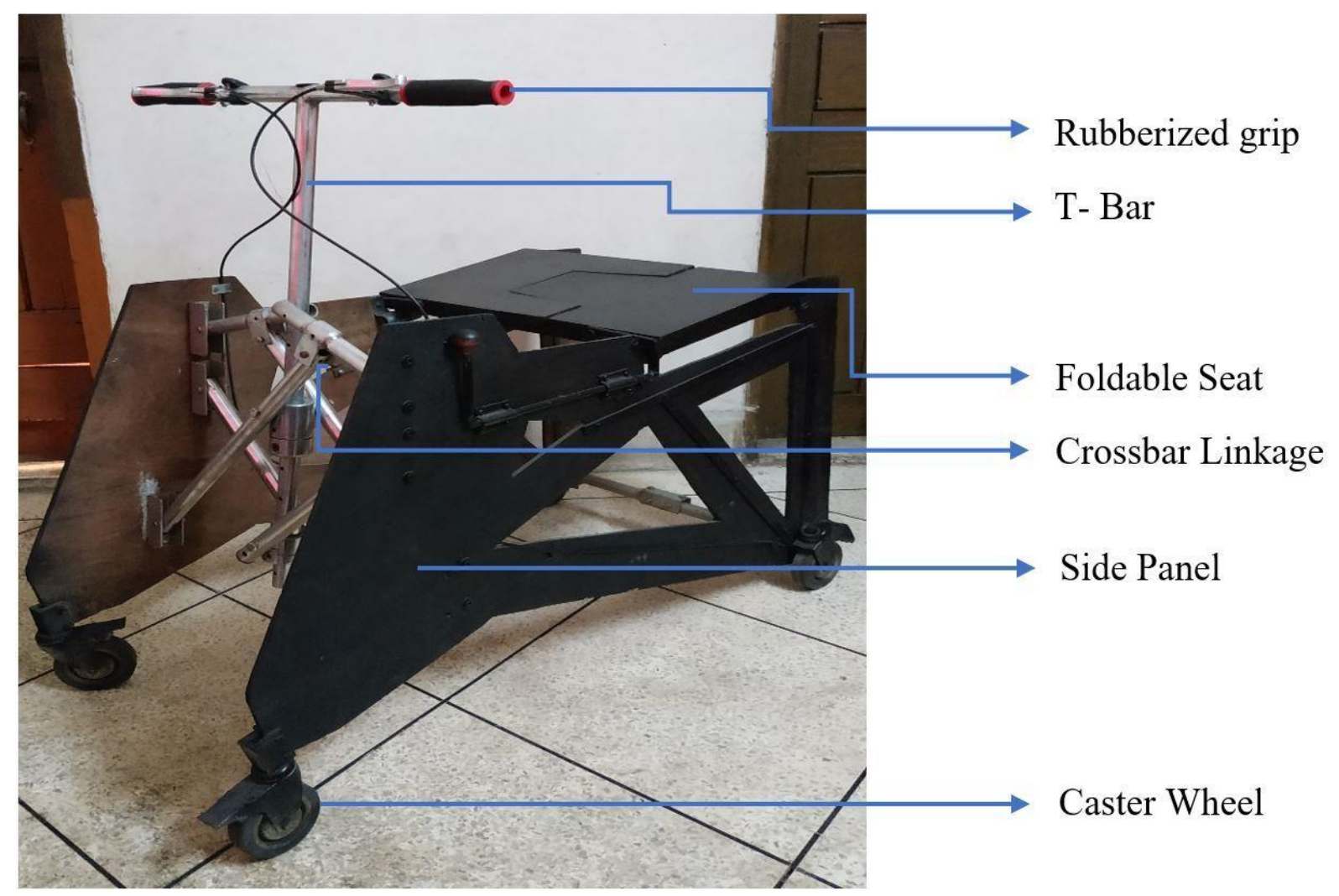

Fig. 5 Manufactured walker indicating the major components

\section{Discussion}

The walker can assist a patient of any height to stand up straight when walking and it has the potential to increase patients' mobility and give them an incentive to go outdoors on their own when there are no caregivers available. The foldable seat is safe and stable, the wheels offer excellent manoeuvrability and the collapsibility makes it easier to carry in transports. All these makes it safely recommendable for use in rehab facilities, nursing homes and hospitals.

Incorporating new technologies in the AD can add more value to it by improving movements and gait condition as addressed in recent researches [25-27] such as by adding further instrumentation, auditory cues to fix unusual gait freezing, and use of visual cues which can potentially improve patient safety while using the walker. Additionally, analysis of stochastic and probabilistic loading on the walker seat using biomechanics for ergonomic consideration 
[28] can improve its design, stability, and manoeuvrability. In case of material consideration, novel eco-friendly natural composites [29] may appear to be more cost-effective for production while aiding in weight minimization with optimized design. All of these have the possibility to make the walker even more suitable for patients with severe issues with coordination of movement. However, it would likely incur higher costs and require more in-depth manufacturing analysis, supply of materials, larger survey audience, affordability, and above all, mindfulness of the patients and their relatives for these instances to happen. The PD patients with higher susceptibility to FoF and balance problems are expected to have poorer quality of life [30] and parkinsonism is still an incurable disease. Thus, the needs of the low-income sufferers deserve to be addressed by the international research community with respect to the use of four-wheeled walkers.

\section{CONCLUSION}

The major thrust of this paper is to reflect on a field survey that was performed with a view to identifying the needs and issues PD patients face when using ADs and designing a generalpurpose walker suitable for their day-to-day lives. The walker has been manufactured on the basis of the specifications derived from the survey using an HOQ model. The simulated FEA results for the safety of use complies with the structural stability of the actual device and it is suitable for use of PD patients and disabled people alike. This walker has the potential to meet the needs of such people with the help of mass production at a more economical price. The project was self-funded and locally executed which would benefit from adequate funds and resources. Forthcoming endeavours may deal with its advancement of features, implications of mass production and raising awareness about PD among people.

\section{ACKNOWEDGEMENT}

Technical guidelines were provided by the Department of Mechanical and Production Engineering, Ahsanullah University of Science and Technology, Dhaka, Bangladesh.

\section{REFERENCES}

[1] Maryland, B. "Parkinson's Disease: Hope Through Research", no. December. National Institute of Neurological Disordres and Stroke, National Institute of Health, pp. 1 - 50, 2014.

[2] Jankovic, J. "Parkinson's disease: clinical features and diagnosis", J. Neurol. Neurosurg. Psychiatry 1957, pp. 368 - 376, 2008.

[3] Reeve, A., Simcox, E., Turnbull, D. “Ageing and Parkinson's disease: Why is advancing age the biggest risk factor?", Ageing Res. Rev. 14 (1), pp. 19 - 30, 2014.

[4] Calabrese, V. P., et al. "Projected Number of People With Parkinson Disease in the Most Populous Nations, 2005 Through 2030”, Neurology 69 (2), pp. 223 - 224, 2007.

[5] Bryant, M. S., Rintala, D. H., Graham, J. E., Hou, J. G., Protas, E. J. "Determinants of use of a walking device in persons with Parkinson's disease.", Arch. Phys. Med. Rehabil. 95 (10), pp. 1940 - 1945, 2014.

[6] Cubo, E., Moore, C. G., Leurgans, S., Goetz, C. G. "Wheeled and standard walkers in Parkinson's disease patients with gait freezing”, Park. Relat. Disord. 10 (1), pp. 9 - 14, 2003.

[7] Rahman, S., Griffin, H. J., Quinn, N. P., Jahanshahi, M. "On the nature of fear of falling in Parkinson's disease”, Behav. Neurol. 24 (3), pp. 219 - 228, 2011.

[8] Kegelmeyer, D. A., Parthasarathy, S., Kostyk, S. K., White, S. E., Kloos, A. D. "Assistive devices alter gait patterns in Parkinson disease: Advantages of the four-wheeled walker", Gait Posture 38 (1), pp. $20-24,2013$. 
[9] Constantinescu, R., Leonard, C., Deeley, C., Kurlan, R. “Assistive devices for gait in Parkinson's disease", Park. Relat. Disord. 13 (3), pp. 133 - 138, 2007.

[10] Hauser, J. R., Clausing, D. “The House of Quality”, Harvard Business Review, pp. 63 - 73, 1988.

[11] Stevens, R. W. "Folding mechanism for a wheelchair", US6572133B1, 2003.

[12] "DINED anthropometric database." [Online]. Available: https://dined.io.tudelft.nl/en/database/tool. [Accessed: 16-Jan-2020].

[13] Doherty, K. M., et al. "Postural deformities in Parkinson's disease", Lancet Neurol. 10 (6), pp. $538-549,2011$.

[14] "Causes and Corrections of Caster Flutter." [Online]. Available: https://www.casterconcepts.com/solutions/ergonomic-casters/causes-and-corrections-of-casterflutter/. [Accessed: 15-Apr-2020].

[15] Figueiredo, J. L., Bernardo, C., Baker, R. T. K., Hüttinger. K. J., Eds. ”Carbon Fibers Filaments and Composites", Springer Netherlands, 1990.

[16] "HexPly 8552 Epoxy Matrix," Product Data Sheet. [Online]. Available: https://www.hexcel.com/user_area/content_media/raw/HexPly_8552_us_DataSheet.pdf. [Accessed: 22-Nov-2019].

[17] Groover, M. P. "Fundamentals of Modern Manufacturing", 4th ed. Wiley, 2010.

[18] "HexPly Prepreg Technology." [Online]. Available: https://www.hexcel.com/user_area/content_media/raw/Prepreg_Technology.pdf. [Accessed: 20Feb-2020].

[19] "SP Systems Guide to composites." [Online]. Available: http://www.composites.ugent.be/home_made_composites/documentation/SP_Composites_Guid e.pdf. [Accessed: 20-Feb-2020].

[20] Callister, W. D., Jr. "Materials Science and Engineering: An Introduction”, 9th ed. Wiley, 2014.

[21] Roylance, D. "Mechanical properties of materials", MIT, 2008.

[22] Kissell, J. R., Ferry, R. L. "Aluminum Structures: A Guide to Their Specifications", 2nd ed. John Wiley \& Sons, Inc., 2002.

[23] Stienstra, D. "Introduction to Design for (Cost Effective) Assembly and Manufacturing." [Online]. Available: http://me.gatech.edu/files/capstone/L071ME4182DFA. [Accessed: 20-Apr2020].

[24] Swift, K. G., Booker, J. D. "Manufacturing Process Selection Handbook", 1st ed. Elsevier Ltd, 2013.

[25] Aharonson, V., Seedat, N., Schlesinger, I., McDonald, A., Dubowsky, S., Korczyn, A. "Feasibility of an instrumented walker to quantify treatment effects on Parkinson's patient gait", in 2018 Electric Electronics, Computer Science, Biomedical Engineerings' Meeting, EBBT 2018, pp. $1-4,2018$.

[26] Mou, W. H., Chang, M. F., Liao, C. K., Hsu, Y. H., Tseng, S. H., Fu, L. C. "Context-aware assisted interactive robotic walker for Parkinson's disease patients", in IEEE International Conference on Intelligent Robots and Systems, pp. 329 - 334, 2012.

[27] Wu, H. K., Chen, H. R., Chen, W. Y., Lu, C. F., Tsai, M. W., Yu, C. H. "A novel instrumented walker for individualized visual cue setting for gait training in patients with Parkinson's disease", Assist. Technol., pp. 1 - 11, 2018.

[28] Frydrýšek, K., Čepica, D., Halo, T. "Stochastic loading of a sitting human", Strojnícky časopis Journal of Mechanical Engineering 69 (2), pp. 97 - 110, 2019. DOI: 10.2478/scjme-2019-0020

[29] Ranakoti, L., Pokhriyal, M., Kumar, A. "Natural fibers and biopolymers characterization: Future 
Potential Composite Material”, Strojnícky časopis - Journal of Mechanical Engineering 68 (1), pp. 33 - 50, 2018. DOI: 10.2478/scjme-2018-0004

[30] Franchignoni, F., Martignoni, E., Ferriero, G., Pasetti, C. "Balance and fear of falling in Parkinson' s disease”, Parkinsonism Relat. Disord. 11, pp. 427 - 433, 2005. 